\title{
High-power microwaves against locusts and other harmful animals
}

\author{
V.E. Zapevalov \\ Institute of Applied Physics RAS, Nizhny Novgorod, Russia, zapev@appl.sci-nnov.ru
}

The locust is an insect that combines several types, usually collected in giant flocks, numbering several million individuals [1-3]. The damage it causes to plants, incomparable. Locusts can destroy all the plants in its path, and its invasion has always been a universal scourge. Innumerable flocks of these insects destroyed the crops, which inevitably led to mass starvation.

Locusts, acridia - several species of insects of the present locust family (Acrididae), capable of forming large flocks (up to hundreds of millions of individuals) migrating to considerable distances. A feature of biology of the locust is the presence of two phases - single and herd. Herd and single locust phases have significant differences, both in appearance and physiology, and in the nature of behavior. Locusts of a single phase usually have a protective coloration, a well-defined sexual dimorphism, and a low-active solitary lifestyle. Insects of the gregarious phase are colored more brightly and contrastively, adults are more adapted to flight. Locusts in this phase behave much more actively are formed larvae or adults. There is practically no sexual dimorphism in the herd phase. Locust has in its life cycle such stages: eggs, then larvae, the latter - imago (fig. 1). The larvae moult 5 times and after the final moult they have wings, the imago stage begins.

The hordes of locusts are able to move at a speed of $15-20 \mathrm{~km} / \mathrm{h}$ and fly without interruption for up to $20 \mathrm{~h}$ in a row. Huge living clouds of locusts sometimes reach $10 \mathrm{~km}$ in width and up to $200 \mathrm{~km}$ in length. Two to three days of tailwind is enough for locusts to attack even remote areas of Russia.

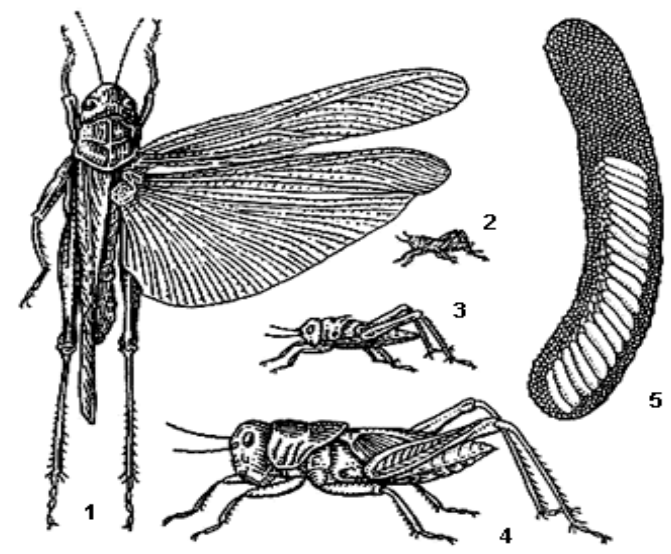

Fig. 1. Locusts: 1 -adult insect; $2-4$ - larvae of the 1 st, $3 \mathrm{rd}$ and 5 th instar; 5 - pod (the side wall is removed)

The fight against this evil is conducted worldwide, but almost all methods used have a strong negative impact on the environment [1-3]. Of course, in the late XX-early XXI centuries researchers have the opportunity to obtain fundamentally new data on these insects with the help of molecular-genetic, biochemical and information methods.
This especially applies to the mechanisms of the transition from a single phase to a herd and back, migrations of swarms and flocks, and so on. However, these opportunities are often not implemented. This is largely due to the fact that interest in these insects (as well as research funding) falls sharply after the suppression of another outbreak, when the danger for agriculture passes. The ultimate goal in locust control is the use of preventive and proactive methods that disrupt the environment to the least possible extent. This would make agricultural production easier and more secure in the many regions where growing crops is of vital importance to the survival of the local people.

In this publication we are going to demonstrate that for control and suppression of locust (and other harmful animals) it is appropriate to use of high-power microwave systems. Important issues are the selection of the frequency range and the required power level for creating mobile microwave complexes. These conditions are determined by technical and economic factors, availability and cost of necessary sources of microwave radiation|, transportation (radiation and propagation) of electromagnetic waves, detection of insects and influence on egg capsules, kuligas (larvae), flocks (imago).

The characteristic number of individuals in the migratory flock of locusts is $N \sim 10^{7}-10^{9}$ pieces with a density of individuals $\mathrm{n} \sim 10^{-3}-10 \mathrm{~m}^{-3}$. Mass of locust specimen $\sim 3 \mathrm{~g}$. The characteristic value of biomass in the flock is up to 3000 tons. The time of flock in flight is $\sim 12 \mathrm{~h}$ per day. Locust locating by infrared radiation can be remotely conducted using thermal imagers since the temperature of the clusters is noticeably higher than the underlying surface. Radar and visual methods can also be used.

Important issue is the selection of the frequency range and required power levels for exposure to different insects. Fig. 3 shows absorption of microwaves by water (pure and with salt) as function of wavelength [4, 5]. Such absorption of microwaves by water at the body of insects (pure and mainly with salt as hemolymph) effects on egg-caps, larvae and flocks of imago. In view of the specific structure of insects (fig. 4), effects of microwaves on them are stronger than for mammals. All vital locust organs are located close to the surface [1-3], within the skin layer, in contrast to mammals (and in general vertebrates) where $83 \%$ of the energy of this radiation is absorbed by the upper layer of the skin.

For effects on eggs and larvae, it is advisable to use a high-efficient magnetrons and gyrotrons $[6,7]$ at the ISM frequencies $((0.915,2.45,5.8,24.125 \mathrm{GHz}$ etc.). Requirements for magnetron and gyrotron type devises for complexes against locust could be discussed. It is reasonable that due to technical and economical reason preferable power level now is $1-3 \mathrm{~kW}$ for magnetron (total power of complex near $100 \mathrm{~kW}$ ) and order of $100 \mathrm{~kW}$ for gyrotron. 
In adult stage (imago) locust clusters the clear advantages have gyrotron systems of mm range similar nonlethal weapons [8]. Fig 5 shows vehicle-mounted Active Denial System. This advanced system uses CPI's VGB8095 gyrotron to generate a $95 \mathrm{GHz}, 100 \mathrm{~kW}$ beam which provides a safe but effective deterrent. Similar Chinese system, known as the Poly WB-1, uses millimeter-wave beams (near $30 \mathrm{GHz}$ ) to scald targets from up to a kilometer away.

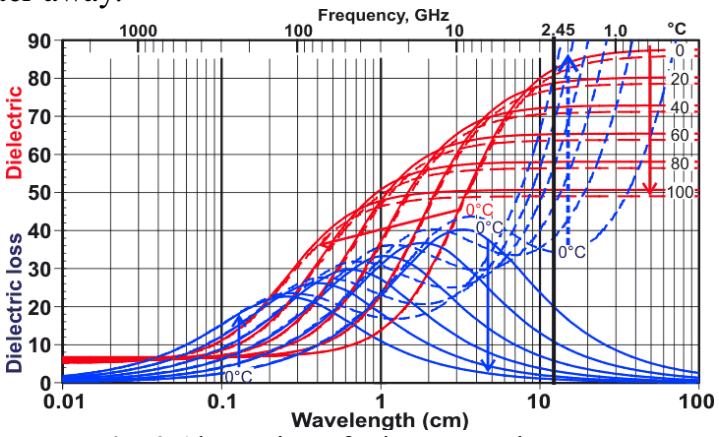

Fig. 3 Absorption of microwaves by water (pure - solid lines, and with salt - dashed lines)

It could be promising to use gyrotron working at the gyro frequency harmonics [7-10]. Fig. 6 demonstrates power and efficiency of gyrotron at the $2^{\text {nd }}$ harmonics of cyclotron frequency (the $\mathrm{TE}_{03}, \mathrm{n}=2, \lambda_{\mathrm{o}} \approx 12 \mathrm{~mm}$, $f_{0} \approx 25 \mathrm{GHz}$ ) vs. beam current and shows prototype of possible industrial version. Some other acceptable version of gyrotrons for such system described at [10]. For those systems RF beam control by phased array antenna it will be practically useful possibility of frequency tuning of RF source $[6,7]$.

For those systems RF beam control by phased array antenna it will be practically useful possibility of frequency tuning of RF source.

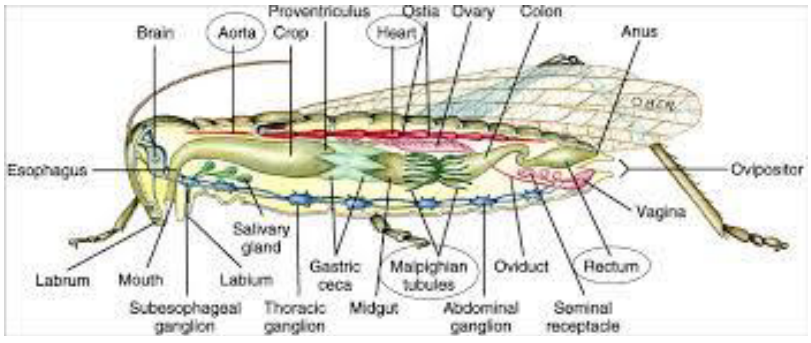

Fig. 4. Scheme of locust and its organs
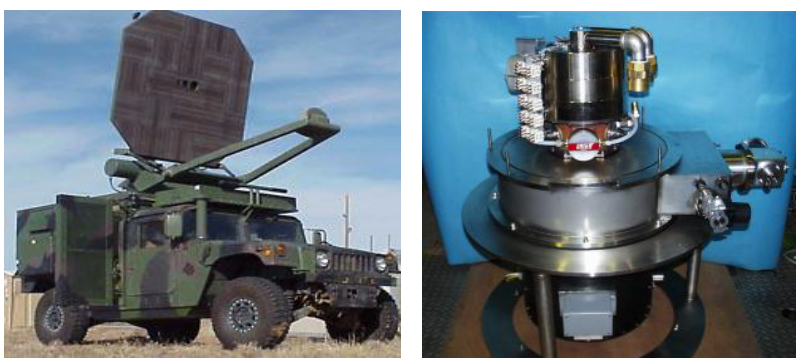

Fig. 5. Active denial system and gyrotron

There are a lot of other phytophagous and harmful animals of agriculture and forestry in our country and the entire world. The possibility of using similar microwave systems to combat other harmful animals, pests of agriculture and forestry could be developed also.
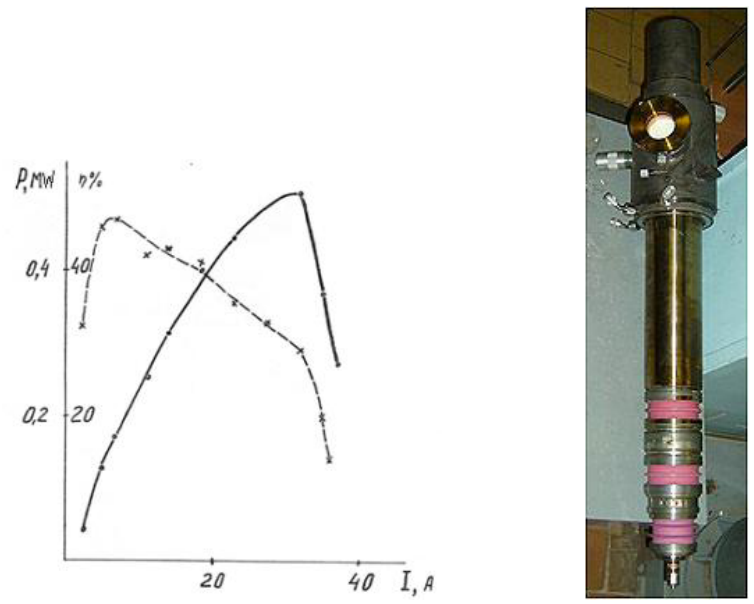

Fig. 6. Power and efficiency of $2^{\text {nd }}$ harmonics gyrotron and prototype of possible industrial version

\section{Summary}

It is advisable to use high-power microwaves to control locusts and other harmful animals.

Locust locating by infrared radiation can be remotely conducted using thermal imagers because the temperature of the clusters is noticeably higher than the underlying surface.

Due to the peculiarities of the structure of insects, the effect of microwaves on them is stronger than on mammals.

To influence the laying of eggs and larvae, it is advisable to use high-efficiency magnetrons and gyrotrons at ISM frequencies. At the adult stage, gyrotron systems, analogous to non-lethal weapons, have clear advantages. The most attractive versions of magnetron and gyrotrons complexes for above mentioned tasks were pointed out.

This work was supported by the Russian Foundation for Basic Research, grant 15-42-02380.

\section{References}

1. Resh V.H. (ed.), Carde R.T. (ed.). Encyclopedia of Insects. Academic Press. 2003. p.666-669.

2. A. Steedman, (ed). 1990. Locust Handbook (3rd edition). Chatham: Natural Resources Institute. 204 pp.

3. B.Uvarov, 1966. Grasshoppers and locusts, V. I. Cambridge: University Press. $481 \mathrm{pp}$.

4. J. B. Hasted, Liquid water: Dielectric properties, in Water A comprehensive treatise, Vol 1, Ed. F. Franks (Plenum Press, New York, 1972) pp. 255-309.

5. Sh.E. Tsimring, Electron beams and microwave vacuum electronics, John Wiley and Sons, Inc., Hoboken, New Jersey, 2007.

6. M.Thumm. State-of-the-Art of High Power GyroDevices and Free Electron Masers. KIT Scientific Publishing, 2014.

7. V.E.Zapevalov, Evolution of gyrotrons, Radiophysics and Quantum electronics, 2011, v. LIV, №8-9, pp. 559-572.

8. V.E.Zapevalov, S.A.Malygin, Sh.E.Tsimring, Gyrotrons at the second harmonic of the cyclotron frequency. In the book: Gyrotrons, Gorky. IAP, 1980, pp.171-187.

9. A.N.Kuftin, V.A.Flyagin, V.K.Lygin, et al. 5.8-62 GHz cw gyrotrons with warm and permanent magnets for technological application. Proc. of Int. workshop "Strong Microwaves in Plasmas”, 1999, N. Novgorod, 2000. pp. 671-676. 